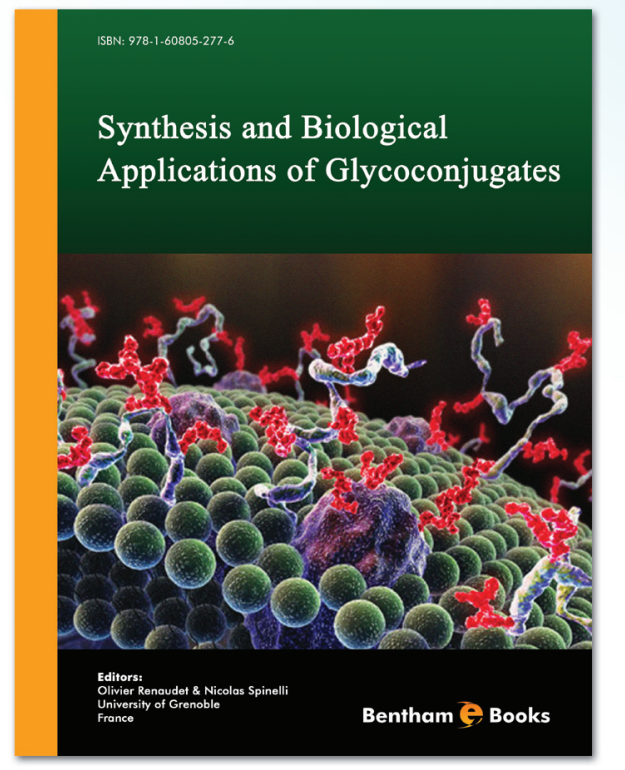

\title{
Editors:
}

Olivier Renaudet

France

Nicolas Spinelli

France

eISBN: 978-1-60805-277-6

\section{Synthesis and Biological Applications of Glycoconjugates}

\section{wwwhenthamseience.com/ehooks/9781608052716}

\section{About the ebook}

Synthesis and Biological Applications of Glycoconjugates gives a summary of contemporary findings in glycoconjugate research. Readers will be updated on major achievements in chemical methods and biological applications employed in modern glycomics. The Ebook should be of interest to a broad community of students and professional researchers in both academia and industry.

\section{Contents}

Bacterial Lectins and Adhesins: Structures, Ligands and Functions

- Ligands for FimH

- Multivalent Glycocalixarenes

- Solving Promiscuous Protein Carbohydrate Recognition Domains with Multivalent Glycofullerenes

- Monovalent and Multivalent Inhibitors of Bacterial Toxins

- Monovalent and Multivalent Glycoconjugates as High Affinity Ligands for Galectins

Combinatorial Libraries of Dendritic Glycoclusters

For Sales Advertising Inquiries: Contact: marketing@benthamscience.org 